\title{
OPTIMIZATION OF MILK TYPE AND PHYSICAL FACTORS FOR REDUCTION OF ALCOHOL CONTENT IN KEFIR
}

Abou Ayana, I. A. A. ${ }^{1}$ and Wesam I. A. Saber ${ }^{2}$

${ }^{1}$ Department of Dairy Research, Food Technology Research Institute (FTRI), Agricultural

Research Centre, Giza, Egypt

${ }^{2}$ Microbial Activity Unit, Department of Microbiology, Soils, Water and Environment Research Institute, Agricultural Research Center, P.N. 12619, Giza, Egypt

\begin{abstract}
Milk kefir beverage has enormous health benefits. However, alcohol content in kefir may represent a barrier for some consumers, so this work attempts to reduce its alcohol content. Three main factors, i.e., the type of milk, inoculum size and incubation temperature were investigated. Results showed that cow's milk inoculated with $2 \%$ kefir grains (KG) and incubated at $24^{\circ} \mathrm{C}$ for $48 \mathrm{~h}$ had the lowest ethanol concentration (EC), however, ewe's milk and soymilk contained the highest EC. According to EC in the previous experiment, buffalo's, cow's and goat's milk were selected to prepare milk kefir. Cow's milk kefir (CMK) had the lowest EC $(0.062 \pm 0.041)$, while, goat's milk kefir (GMK) had the highest EC $(0.093 \pm 0.021)$ at zero time. Moreover, buffalo's milk kefir (BMK) had the highest $\mathrm{pH}$, total solids, acetaldehyde, lactose and viscosity. Statistically, after 10 d BMK won the greatest Overall quality (5.825) while CMK came in the second place (5.355) then GMK (5.310).

Keywords: kefir, ethanol content, buffalo's, cow's, goat's, ewe's milk, soy milk.
\end{abstract}

\section{INTRODUCTION}

Kefir is of Caucasus origin, being made in Mountains of Russia. It has been credited with various health promoting properties (Liu et al., 2005). This fermented milk beverage is a result of microbial action of a wide combination of lactic and acetic acid bacteria in addition to various yeasts exist in gelatinous white or yellow particles known as "kefir grains" that can ferment mammal's milk, milk substitutes and other sugary liquids. The attributes of kefir are creamy consistency, viscous, a slightly acidic taste and some effervescence, the final product contain lactic and acetic acid, acetaldehyde, diacetyl, acetoin, ethanol $(<2 \%)$, carbon dioxide and free fatty acids (Leite et al., 2013a).

The usual daily consumption of the fermented dairy foods known as probiotics, such as kefir, has tremendous health benefits including; (1) therapeutic effects such as prevention of urogenital infection, synthesis of vitamins (B2, B6, and B12), prevention of diarrheae and prevent skin problem; immunomodulation including prevention of respiratory diseases, and improve resistance to allergies; (3) improving intestinal microbial structure leading to prevention of irritable bowel syndrome, support digestive process, prevention of exogenous pathogen (e.g. traversal's diarrhea) and prevention endogenous (e.g. antibiotic associated diarrhea); and (4) metabolic effects include lactose hydrolase (improve lactose digestion), bile salt de-conjugation (bile salt hydrolase), cholesterol reduction, lower the toxigenic / mutagenic reduction in gut, anti-carcinogenic activity, enhance calcium metabolism and prevent osteoporosis (Anandharaj et al., 2014). Despite the enormous health benefits of kefir, the presence of alcohol is an obstacle to use it in Arab countries because of the traditions and religion habits that deplore the presence of alcohol in food and drinks.

Hence the main goal of this work was to study certain nutritional and physical factors affecting reducing alcohol content in kefir for making milk kefir beverage with as little as possible of alcohol with retaining nutritional and healthy benefits of kefir.

\section{MATERIALS AND METHODS}

Fresh whole buffalo's, cow's, ewe's and goat's milk were obtained from El-Serw experimental station, Animal Production Research Institute, Agricultural Research Center, Egypt. Soybeans (Giza 111) were obtained from Tagelez Research Station, Crops Research Institute, Agricultural Research Center, Egypt. Soy milk was prepared according to Kasenkas et al. (2011) with slight modifications. The soybeans seeds were washed and soaked overnight in distilled water. After decanting the water, the soaked soybeans were mixed with 3 times of their weight of distilled water, blended and filtered. All milks used in this study were analyzed for gross chemical composition as indicated in (Table, 1).

Table 1: Gross chemical composition of used milks.

\begin{tabular}{lcccccc}
\hline Type of milk & Fat & Lactose & $\begin{array}{c}\text { Ingredient, \% } \\
\text { Protein }\end{array}$ & TS & Acidity & pH \\
\hline Buffalo & 5.7 & 4.46 & 4.42 & 15.38 & 0.16 & 6.51 \\
Cow & 3.9 & 4.37 & 3.59 & 12.66 & 0.17 & 6.68 \\
Ewe & 6.3 & 5.61 & 4.7 & 17.39 & 0.17 & 6.53 \\
Goat & 3.8 & 4.46 & 3.28 & 12.32 & 0.15 & 6.57 \\
Soy & 2.18 & 2.91 (As carbohydrate) & 3.53 & 10.3 & 0.12 & 6.74 \\
Skimmed & 0.2 & 4.8 & 4.6 & 10.5 & Not measured & Not measured \\
\hline
\end{tabular}


Kefir grains were kindly provided by the Department of Food Engineering, Suleyman Demirel University, Isparta, Turkey. For activation, sterilized skim milk was inoculated with fresh washed kefir grains (with sterile water) at level of $5 \% \mathrm{w} / \mathrm{v}$, then incubated at $25{ }^{\circ} \mathrm{C}$ for $24 \mathrm{~h}$ and the medium was exchanged daily, this process being necessary to maintain the grains' viability.

For fermenting and detecting of kefir ethanol content, $50 \mathrm{ml}$ of each milk type (standardized $3 \%$ fat) was sterilized $\left(121^{\circ} \mathrm{C}\right.$ for $\left.15 \mathrm{~min}\right)$, cooled to $25^{\circ} \mathrm{C}$ and individually inoculated with active KG ( 2 or $4 \%$ ) mixed well, and one $\mathrm{ml}$ of each was added in test tube $(15 \times 125 \mathrm{~mm})$. The tubes were hung in airtight $250-\mathrm{ml}$ flasks containing $25 \mathrm{ml}$ of potassium dichromate (33.768 $\mathrm{g}$ of $\mathrm{K}_{2} \mathrm{Cr}_{2} \mathrm{O}_{7}$ dissolved in $400 \mathrm{ml}$ of distilled water with $325 \mathrm{ml}$ of sulfuric acid and volume raised to $1 \mathrm{~L})$ solution that acted as recipient for the formed alcohol. All flasks were incubated at 24 or $28^{\circ} \mathrm{C}$ for 48 hours.

Alcohol was determined in the fermented milks according to Caputi et al. (1968) with slight modification. Briefly, after incubation, every test tube was removed then $30 \mathrm{ml}$ of distilled water was added on the inner wall of flask and mixed well with $\mathrm{K}_{2} \mathrm{Cr}_{2} \mathrm{O}_{7}$, about $20 \mathrm{ml}$ of distillate was collected from each sample and the flasks were kept in a water bath at $62.5^{\circ} \mathrm{C}$ for 20 minutes, cooled to room temperature and the volume was raised to $50 \mathrm{ml}$, the optical density was spectrophotometrically measured at $600 \mathrm{~nm}$, the data were calibrated by various standard curves made from ethanol for each condition.

Foe examining milk type, temperature and time of incubation vs $\mathrm{KG}$ biomass, $25 \mathrm{ml}$ of each type of milks was sterilized $\left(121^{\circ} \mathrm{C}\right.$ for $\left.15 \mathrm{~min}\right)$ and inoculated with $2 \% \mathrm{KG}(\mathrm{A})$. The inoculated flasks were incubated at 24 or $28{ }^{\circ} \mathrm{C}$ for 24 or $48 \mathrm{~h}$. After each experiment, all formed $\mathrm{KG}$ were separated by a narrow colander, washed and left in air for 5 min then weighted (B). The variation in biomass (BM \%) was calculated as follows; $\mathrm{BM} \%=(\mathrm{B}-\mathrm{A}) / \mathrm{A} \times 100$.

The KG grown in various milks were separated under sanitization condition, two slices from each grain were stained using Safranin simple staining. The microbial structure of the $\mathrm{KG}$ were light microscopically examined using oil-immersion lens.

For making of kefir, milks (standardized 3\% fat), heated to $95{ }^{\circ} \mathrm{C}$ for $15 \mathrm{~min}$ and immediately cooled to $23{ }^{\circ} \mathrm{C}$ then, inoculated with active $\mathrm{KG}(2 \% \mathrm{w} / \mathrm{v})$ and incubated at $24{ }^{\circ} \mathrm{C}$ until $\mathrm{pH}$ fall to $\sim 4.7$. After Table 2: Effect of milk type, inoculum size and temperature on kefir alcohol content.

\begin{tabular}{|c|c|c|c|}
\hline \multirow{2}{*}{ Inoculum, \% } & \multirow{2}{*}{ The type of milk } & \multicolumn{2}{|c|}{ Ethanol, $\% \pm 2$ SD } \\
\hline & & Incubation at $24^{\circ} \mathrm{C}$ & Incubation at $28^{\circ} \mathrm{C}$ \\
\hline \multirow{5}{*}{2} & Buffalo & $0.180 \pm 0.035$ & $0.194 \pm 0.061$ \\
\hline & Cow & $0.125 \pm 0.045$ & $0.181 \pm 0.040$ \\
\hline & Goat & $0.207 \pm 0.068$ & $0.221 \pm 0.040$ \\
\hline & Ewe & $0.222 \pm 0.045$ & $0.254 \pm 0.061$ \\
\hline & Soy & $0.252 \pm 0.093$ & $0.308 \pm 0.046$ \\
\hline \multirow{5}{*}{4} & Buffalo & $0.187 \pm 0.068$ & $0.207 \pm 0.046$ \\
\hline & Cow & $0.155 \pm 0.093$ & $0.214 \pm 0.061$ \\
\hline & Goat & $0.207 \pm 0.093$ & $0.254 \pm 0.023$ \\
\hline & Ewe & $0.244 \pm 0.090$ & $0.294 \pm 0.061$ \\
\hline & Soy & $0.267 \pm 0.162$ & $0.361 \pm 0.040$ \\
\hline
\end{tabular}

incubation, the grains were separated by a narrow colander from kefir beverages. The Kefir samples were chemically, microbiologically and organoleptically analyzed at the zero, $7^{\text {th }}$ and $15^{\text {th }}$ day of storage period. The trials were performed in triplicates. Milk protein, milk fat, $\mathrm{pH}$, acidity (TA), total solids (TS), lactose (L) of milk kefir beverages were determined according to AOAC (2003). Soymilk fat was determined by method described by Pearson (1981). Acetaldehyde (A) was measured (mg/L) using a Shimadzu (240 UV-vis) spectrophotometer (Japan) as described by Lees and Jago (1970), alcohol content (EC) was determined using spectrophotometer according to Caputi et al., (1968) with some modifications. To measure viscosity (V) of Kefir, each sample $(100 \mathrm{~mL})$ was placed in a viscometer (LVDV11+P, Brookfield, USA) and the viscosity (cPs) was measured between 5 to $8 \mathrm{~min}$ with a one minute period at $12 \mathrm{rpm}$.

Yeast counts were enumerated according to Van der Walt and Yarrow (2009), ten grams of each sample was taken, diluted in $90 \mathrm{ml}$ of sterile solution of $2 \%$ $(\mathrm{w} / \mathrm{v})$ sodium citrate and homogenized in a Stomacher for $30 \mathrm{~s}$. to obtain tenfold dilutions. yeast were determined by surface plating on yeast potato dextrose agar (PDA) with $0.01 \%$ of chloramphenicol, after incubated at $25{ }^{\circ} \mathrm{C}$ for 3 days.

Lactic acid bacteria (LAB) were determined on De Man, Rogosa (MRS) agar and incubated at $37^{\circ} \mathrm{C}$ for 48h. specialists, who received an explanation of the goal of test, the evaluation methods used and the test parameters. The sensory properties included appearance, flavor \& odor, sourness, texture and overall quality. The score ranges were from 1 (poor) to 7 (excellent). The samples were presented in a triplicate cups in random order and coded with three digit random numbers. The organoleptic properties of fresh obtained kefir samples and after 10 days were evaluated.

\section{RESULTS AND DISCUSSION}

Alcohol content in kefir is the critical point in this work, Three main factors that are expected to play an important role to reduce kefir alcohol content were studied, i.e. the type of milk, inoculum size and incubation temperature. Data presented in Table 2 show the ethanol concentration $\%$ (EC) as a result of the previous mentioned factors.
For the sensory analysis, ten of dairy science 
In general, all factors studied affected on kefir ethanol content. Regarding the type of milk, Cow's milk inoculated with $2 \% \mathrm{KG}$ and incubated at $24^{\circ} \mathrm{C}$ for $48 \mathrm{~h}$ contained the lowest EC $(0.125 \%)$, followed by buffalo's milk $(0.180 \%)$. On the other hand, increasing the incubation temperature from $24{ }^{\circ} \mathrm{C}$ to $28^{\circ} \mathrm{C}$ at the same inoculum size $(2 \%)$ resulted in to slight increase in the ethanol content of kefir. However, an obvious difference was observed at $4 \%$ inoculum size when rising incubation temperature from $24{ }^{\circ} \mathrm{C}$ to $28{ }^{\circ} \mathrm{C}$. Therefore, the type of milk as a growth medium, the incubation temperature and inoculum size were influential factors on the ethanol content of kefir.

kefiran plays an important role in the kefir quality (slimy and gummy) as well as the therapeutic effects. It has a great role in KG biomass (BM), in this respect, three important factors were investigated, i.e. the type of milk, incubation temperature and incubation time. Data listed in Table 3 indicate that BM\% directly affected by the type of milk, after $24 \mathrm{~h}$ of incubation at $24{ }^{\circ} \mathrm{C}$, buffalo's and ewe's milk produced the highest increase in BM\% (34), soy milk (30) then cow's and goat's milk (24) came next. With the prolongation of incubation time up to $48 \mathrm{~h}$, lower BM\% were recorded by $28,20,30,20$ and $26 \%$ for buffalo's, cow's, ewe's, goat's milk and soy milk, respectively. Also, raising the incubation temperature resulted in a decline in $\mathrm{BM} \%$ significantly, whither for 24 or $48 \mathrm{~h}$, but prolong the incubation period to $48 \mathrm{~h}$ at $28{ }^{\circ} \mathrm{C}$ dropped $\mathrm{BM} \%$ sharply. Hence, $24^{\circ} \mathrm{C}$ for $24 \mathrm{~h}$ were the most suitable conditions to produce maximum biomass.

Milk type and its chemical composition (proteins, lipids, carbohydrates, minerals and vitamins), impacted on KG biomass (Table 3), leading to variation in the resulted KG biomass. In this respect, Pop et al., (2014) reported that biomass of KG greatly affected by the type of milk, and the organic skim milk incubated at $25^{\circ} \mathrm{C}$ for $24 \mathrm{~h}$ with a rotation rate of $125 \mathrm{rpm}$ were the optimal conditions for produce the highest KG biomass. These results might be attributed to the kind of substrates, necessary for the growth of KG. Surely, the incubation temperature at $28{ }^{\circ} \mathrm{C}$ affected negatively on $\mathrm{BM} \%$, and positively on $\mathrm{EC} \%$ more than $24^{\circ} \mathrm{C}$. This means that at high incubation temperature the milk compounds are consumed by KG microorganisms for the formation of alcohol rather than $\mathrm{KG}$ kefiran. Additionally, casein is also important factor that reported to increase $\mathrm{KG}$ biomass by its positive effect on kefiran which increased by rising casein in buffalo's and ewe's milk, according to Wang and Bi (2008) who confirmed that biomass include kefiran reached the maximum value in the presence of casein.

Table 3: Effect of milk type, incubation time and temperature on the biomass of Kefir grains.

\begin{tabular}{|c|c|c|c|c|c|c|c|c|}
\hline \multirow{3}{*}{$\begin{array}{l}\text { The type } \\
\text { of milk }\end{array}$} & \multicolumn{4}{|c|}{ Incubation at $24^{\circ} \mathrm{C}$} & \multicolumn{4}{|c|}{ Incubation at $28^{\circ} \mathrm{C}$} \\
\hline & \multicolumn{2}{|c|}{$24 \mathrm{~h}$} & \multicolumn{2}{|c|}{$48 \mathrm{~h}$} & \multicolumn{2}{|c|}{$24 \mathrm{~h}$} & \multicolumn{2}{|c|}{$48 h$} \\
\hline & BM, gm & BM, \% & BM, gm & BM, \% & BM, gm & BM, \% & BM, gm & BM, \% \\
\hline Buffalo & 0.67 & 34 & 0.64 & 28 & 0.64 & 28 & 0.61 & 22 \\
\hline Cow & 0.62 & 24 & 0.60 & 20 & 0.59 & 18 & 0.57 & 14 \\
\hline Ewe & 0.67 & 34 & 0.65 & 30 & 0.65 & 30 & 0.62 & 24 \\
\hline Goat & 0.62 & 24 & 0.60 & 20 & 0.60 & 20 & 0.58 & 16 \\
\hline Soy & 0.65 & 30 & 0.63 & 26 & 0.64 & 28 & 0.61 & 22 \\
\hline
\end{tabular}

Because of lack of clarity in the relationship between EC and biomass, the microbial community of $\mathrm{KG}$ were microscopically examined. All KG contained diversity of microbes, the microbial structure of $\mathrm{KG}$ grown in buffalo's milk contained lower load of microorganisms, they were short and long rods, single or double cocci, about three yeast cells/field and smallsized masses of granules. The KG of cow's milk composed from 30-50 cells of yeasts/field in various budding state in masses, various di-, tri- and streptococci, short and long rods in equal numbers. KG grown in ewe's milk showed three cells of yeasts/field, di- and tri-cocci, short and long rods, some masses of granules could also be seen. Very low yeast cells (about two/field), single- or di- cocci, rods (short and long), beside some masses of granules appeared in KG grown in goat's milk. Finally, nearly 5 yeasts cell/ field, singleor di- cocci, rods (single, di, chain short and long) beside some masses of granules could be seen in the film of KG cultivated in soy milk, its grains seemed to be more fragmented.

The increment of yeast counts in case cow's milk may be due to that outer grain portions is suitable for yeasts, unlike bacteria which often located in the inner grain portions, our observation is in consistent with the notes of Leite et al., 2013b).

Generally, Kefir composition is not uniform and not well described (Otles and Cagindi, 2003). Fermented milks usually are stored at low temperatures to prolong the validity period and maintaining its quality. Measurement of $\mathrm{pH}$ and TA of fermented milks is important to determine the quality. The changes of $\mathrm{pH}$ and TA during the storage are shown in Table 4. The initial $\mathrm{pH}$ values were 4.62, 4.58 and 4.66 for BMK, CMK and GMK, respectively. Gradual decreases were observed to reach $4.48,4.51$ and 4.51 after $15 \mathrm{~d}$ of cold storage. Chemically, TA occupied an opposite trend. These ranges of $\mathrm{pH}$ and TA are considered to be in the acceptable range of probiotic fermented milks. The $\mathrm{pH}$ decreases due to increasing acidity in the early stage of storage caused by continued metabolic activity of the fermentation bacteria, e.g. LAB. The $\mathrm{pH}$ and TA values found in this study are considered to be in the acceptable range of a commercial yogurt (Kang et al., 2013). These results for kefir are in agreement with the findings of Yoo et al., (2013). 
Normally, TS kefir content affected by the TS of milks, so BMK had the highest TS followed CMK then GMK. Data shown in Table 4 reveal that TS of Kefir samples compatible with TS of milks and gradually increased along storage. Kefir contains $10.6 \%-14.9 \%$ TS (Wszolek et al., (2001), while Magalhaes et al., (2011a) confirmed that Brazilian Kefir contain 9.62\% dry matter after a day of keeping. The increment of TS may be due to declining of moisture content during storage.

Lactose concentration in fermented dairy products is strongly related to $\mathrm{pH}$ and acidity due to the activity of microorganism, which have the ability to metabolize lactose as energy source. Initial lactose quantities were $3.45,3.35$, and 3.34 , then gradually decreased to reach $3.22,3.15$ and 3.16 after 15 day of cold storage for BMK, CMK and GMK, respectively.

Nutty and pungent aromas are usually detected in fermented dairy products; acetaldehyde is responsible for that aroma. Experimental kefirs contained limited levels of acetaldehyde (Table 4); initial quantities were 7.7, 6.8 and $6.6 \mathrm{mg} / \mathrm{L}$, gradually increased to reach 9.4, 9.1 and $8.73 \mathrm{mg} / \mathrm{L}$ after $7 \mathrm{~d}$ then decreased to reach 8.83, 8.7 and 8.2 for BMK, CMK and GMK, respectively. The low concentrations of acetaldehyde in Kefir beverages probably due to the metabolism of a part of it to alcohol by alcohol dehydrogenase enzyme (Ertekin and GüzelSeydim, 2010). Acetaldehyde is considered the major yogurt or fermented milks flavor. It can be formed by the group of N-streptococci. These microorganisms degrade lactose to galactose and glucose; glucose can be metabolized by the homofermentative Embden-Meyerhof-Parnas pathway to pyruvate, where $2 \mathrm{~mol}$ of lactate is formed per glucose molecule residual pyruvate, catalyzed by an $\alpha$ carboxylase, is then converted to diacetyl and acetaldehyde. An aldehyde dehydrogenase may also generate acetaldehyde from acetyl-CoA, which is formed from pyruvate by the action of a pyruvate dehydrogenase (Yuksekdag et al., 2004 and Geroyiannaki et al. (2007).

Change of viscosity during storage (Table 4) in the different kefir fermented milks was measured along the storage period. The viscosity affected the palatability of fermented milks so it is an important factor in quality of yogurt and kefir. BMK had the highest viscosity (1510 cPs) followed by CMK (1390 cPs), while GMK had the lowest viscosity (1270 cPs). The viscosity of all samples tended to increase slightly at the end of the storage period to reach 1612, 1472 and $1360 \mathrm{cPs}$ after $15 \mathrm{~d}$ of cold storage. Similar results were reported by Yoo et al., (2013), who made kefir by twostep fermentation. The total solids content of the yogurt mixture, the degree of hydrolysis of proteins, the slimeproducing capacity and acid producing capacity of the strain are important factors affect the viscosity of fermented milks (Tamime and Robinson, 1999) as well casein micelles and fat globules most affect the viscosity of milk. The previous factors that increase the viscosity maybe explain our results. Surely, polysaccharides, Mucoid substances, kefiran produced lactic acid bacteria and other microbes increase the kefir viscosity. Casein also plays an important role in the increment of viscosity.

Table 4: Physicochemical properties of experimental kefir samples \pm 2 SD.

\begin{tabular}{|c|c|c|c|c|c|c|c|c|c|}
\hline \multirow{3}{*}{ Item } & \multicolumn{9}{|c|}{ Storage period (days) } \\
\hline & \multicolumn{3}{|c|}{ BMK } & \multicolumn{3}{|c|}{ CMK } & \multicolumn{3}{|c|}{ GMK } \\
\hline & $\mathbf{0}$ & 7 & 15 & $\mathbf{0}$ & 7 & 15 & $\mathbf{0}$ & 7 & 15 \\
\hline$\overline{\mathrm{pH}}$ & $4.62 \pm 0.08$ & $4.51 \pm 0.05$ & $4.48 \pm 0.04$ & $4.58 \pm 0.31$ & $4.56 \pm 0.09$ & $4.51 \pm 0.05$ & $4 . .66 \pm 0.05$ & $4.56 \pm 0.07$ & $4.51 \pm 0.06$ \\
\hline TA & $0.80 \pm 0.04$ & $0.85 \pm 0.07$ & $0.91 \pm 0.04$ & $0.80 \pm 0.16$ & $0.82 \pm 0.05$ & $0.88 \pm 0.04$ & $0.76 \pm 0.07$ & $0.83 \pm 0.06$ & $0.88 \pm 0.07$ \\
\hline TS & $16.25 \pm 0.03$ & $16.42 \pm 0.03$ & $16.54 \pm 0.04$ & $13.15 \pm 0.01$ & $13.24 \pm 0.03$ & $13.38 \pm 0.02$ & $12.27 \pm 0.04$ & $12.42 \pm 0.03$ & $12.55 \pm 0.02$ \\
\hline $\mathrm{L}$ & $3.45 \pm 0.43$ & $3.35 \pm 0.37$ & $3.22 \pm 0.05$ & $3.35 \pm 0.06$ & $3.23 \pm 0.07$ & $3.15 \pm 0.14$ & $3.34 \pm 0.08$ & $3.30 \pm 0.04$ & $3.16 \pm 0.19$ \\
\hline A & $7.7 \pm 0.92$ & $9.4 \pm 1.22$ & $8.83 \pm 1.30$ & $6.80 \pm 0.92$ & $9.1 \pm 0.80$ & $8.7 \pm 0.92$ & $6.6 \pm 1.11$ & $8.73 \pm 0.9$ & $8.2 \pm 1.44$ \\
\hline $\mathrm{EC}$ & $0.082 \pm 0.041$ & $0.134 \pm 0.021$ & $0.168 \pm 0.043$ & $0.062 \pm 0.041$ & $0.103 \pm 0.041$ & $0.137 \pm 0.024$ & $0.093 \pm 0.021$ & $0.156 \pm 0.021$ & $0.206 \pm 0.041$ \\
\hline V & $1517 \pm 13.1$ & $1550 \pm 15.0$ & $1614 \pm 5.3$ & $1389 \pm 8.1$ & $1435 \pm 8.3$ & $1475 \pm 6.0$ & $1273 \pm 6.1$ & $1322 \pm 4.0$ & $1362 \pm 4.0$ \\
\hline
\end{tabular}

TA: Titratable acidity, TS: total solids, L: lactose, A: Acetaldehyde, EC: ethanol, V: Viscosity. BMK: buffalo's milk kefir, CMK: cow's milk kefir, GMK: goat's milk kefir

Cow's, buffalo's and goat's milk kefir showed the lowest level of ethanol content, particularly when inoculated with $2 \%$ inoculum at $24{ }^{\circ} \mathrm{C}$; therefore, these treatments were chosen to produce milk kefir beverages. EC of the kefir samples (BMK, CMK and GMK) during storage is shown in (Table 4). The fresh CMK had the lowest EC (0.062) followed by BMK (0.082) then GMK (0.093), these concentrations tended to increase slightly during the storage period to reach the maximum levels, being $0.137,0.168$ and $0.206 \%$ after $15 \mathrm{~d}$ of cold storage, respectively. Typically, Kefir contains $1.0 \%$ alcohol, comparing to other studies, the final ethanol concentrations were $8.7 \pm 1.6 \mathrm{~g} / \mathrm{l}, 8.3 \pm 0.2 \mathrm{~g} / \mathrm{l}$ and $7.8 \pm$ $0.3 \mathrm{~g} / \mathrm{L}$ for milk kefir, cheese whey kefir and deproteinised cheese whey kefir, respectively (Magalhães et al., 2011b). Kefir products fermented by a conventional method contained a high concentration of alcohol, starting from $1.3 \%$ and up to $1.36 \%$ (Sarkar, 2007 and Yoo et al., 2013). It is well known that there are lot of microbes responsible for the production of ethanol in Kefir; yeasts such as Kluyveromyces marxianus var. lactis, Saccharomyces cerevisiae, Candida inconspicua and Candida maris and Heterofermentative bacteria, e.g. Lactobacillus kefiri and Leuconostoc spp. The amounts of ethanol and $\mathrm{CO} 2$ produced during the fermentation of kefir depend on the production conditions. Moreover, concentration of ethanol in fresh yogurt samples ranged $1.38-4.61 \mathrm{ppm}$ and increased to reach 3.17-8.88 and 4.26-8.75 ppm after $10 \mathrm{~d}$ at $4^{\circ} \mathrm{C}$ and $20{ }^{\circ} \mathrm{C}$, respectively (Hruskar and Milana Ritz, 1995 and Farnworth, 2005)

Yeast and lactobacilli are mutually dependent and grow in balanced proportions in kefir grains, and symbiosis between yeast, lactobacilli and streptococci 
were observed during the production of kefir (Sarkar, 2008). Data presented in (Table 5) show the changes in LAB counts in the experimental kefir samples during cold storage. In fresh samples, LAB recorded 9.13, 8.82 and $9.20 \log \mathrm{cfu} / \mathrm{mL}$, these numbers slightly increased to reach $9.19,9.01$ and $9.28 \log \mathrm{cfu} / \mathrm{mL}$ after $7 \mathrm{~d}$, then limitedly decreased to become $9.17,8.88$ and 9.18 on the fifteenth day of storage of BMK, CMK and GMK, respectively. The differences of these counts might be attributed to the type of milk and their available nutrients. LAB did not change in the first $9 \mathrm{~d}$ of storage, but increased slightly afterwards Leite et al. (2013b); these numbers are within the scope of probiotic in fermented therapeutic products. Therapeutic LAB counts must be $\geq 10^{6}$ in probiotic products so the experimental kefir has therapeutic effects (Yoo et al., (2013).

Table 5: Lactic acid bacteria and yeast counts during cold storage of buffalo's, cow's and goat's milk kefir.

\begin{tabular}{|c|c|c|c|c|c|c|c|c|c|}
\hline \multirow{3}{*}{ Microorganism } & \multicolumn{9}{|c|}{ Counts $(\log \mathrm{CFU} / \mathrm{ml}) \pm 2 \mathrm{SD}$ during storage } \\
\hline & \multicolumn{3}{|c|}{ BMK } & \multicolumn{3}{|c|}{ CMK } & \multicolumn{3}{|c|}{ GMK } \\
\hline & 0 & 7 & 15 & 0 & 7 & 15 & 0 & 7 & 15 \\
\hline LAB & $9.13 \pm 0.031$ & $9.19 \pm 0.04$ & $9.17 \pm 0.69$ & $8.82 \pm 0.061$ & $9.01 \pm 0.07$ & $8.88 \pm 0.07$ & $9.20 \pm 0.061$ & $9.28 \pm 0.06$ & $9.18 \pm 0.06$ \\
\hline Yeasts & $4.31 \pm 0.042$ & $4.61 \pm 0.08$ & $4.82 \pm 0.05$ & $5.18 \pm 0.061$ & $5.38 \pm 0.05$ & $5.54 \pm 0.031$ & $4.46 \pm 0.092$ & $4.74 \pm 0.092$ & $4.91 \pm 0.061$ \\
\hline
\end{tabular}

Yeast counts in experimental kefir samples were $4.31,5.18$ and $4.46 \log \mathrm{cfu} / \mathrm{mL}$ increased gradually to record 4.82, 5.54 and 4.91 at the end of cold storage for BMK, CMK and GMK, respectively. This variation due to contrast milk composition, kefir microflora composition varies according to culture medium and production method (Sarkar, 2008). Yeast levels present in $\mathrm{KG}$ vary widely, ranging from $1.5 \times 10^{5}$ to $3.7 \times 10^{8}$ $\mathrm{cfu} / \mathrm{ml}$ Witthuhn et al. (2004). A total of 66 yeast colonies were isolated from 5 Tibet kefir samples, yeast isolates were classified into 8 groups belonging to the genera: Saccharomyces, Pichia, Debaryomyces, Rhodotorula, Candida, Kluyveromyces and Kazachstania (Li et al., 2015).

Table 6 shows the results of descriptive sensory analysis of BMK, CMK and GMK. Major factors determining the quality of kefir samples are generally appearance, flavor \& odor taste, texture, and overall acceptability. Generally, the evaluation degrees gradually slightly increased during storage. BMK was rated favorably in all sensory parameters to achieve the maximum overall quality at zero (5.290) and after $10 \mathrm{~d}$ (5.825. In spite of cow's milk Kefir was the lowest in appearance; it achieved the second place in overall quality, this perhaps because of increase the other sensory parameters (flavor or odor, sourness and texture). The important note was the disappearance the alcoholic odor, and yogurt aroma which is dominant in the most samples. Raising clean acidity (lactic acid), increase acetaldehyde and viscosity, all these attributes led to high quality, hence increase acceptance rates in all the samples. In spite of the lower evaluation of GMK compared to CMK and BMK, it gains the acceptance. This evaluation nearly harmonized sensory evaluation reported by Yoo et al., (2013).

Table 6: the sensory evaluation of fresh experimental kefir samples and after10 days.

\begin{tabular}{lcccccc}
\hline \multirow{2}{*}{ Kefir samples } & $\begin{array}{c}\text { The time of } \\
\text { evaluation(d) }\end{array}$ & Appearance & Flavor or odor & sourness & texture & Overall quality \\
\hline \multirow{2}{*}{ BMK } & 0 & $5.70 \pm 0.40$ & $5.57 \pm 0.70$ & $4.55 \pm 0.46$ & $5.34 \pm 0.46$ & 5.290 \\
& 10 & $6.22 \pm 0.74$ & $5.90 \pm 0.40$ & $5.59 \pm 0.48$ & $5.59 \pm 0.48$ & 5.825 \\
CMK & 0 & $5.32 \pm 0.35$ & $5.43 \pm 0.51$ & $4.35 \pm 0.59$ & $4.35 \pm 0.59$ & 4.863 \\
& 10 & $5.64 \pm 0.43$ & $5.75 \pm 0.27$ & $4.71 \pm 0.29$ & $5.32 \pm 0.24$ & 5.355 \\
GMK & 0 & $5.53 \pm 0.54$ & $5.21 \pm 0.54$ & $4.40 \pm 0.52$ & $4.75 \pm 0.19$ & 4.973 \\
& 10 & $5.77 \pm 0.31$ & $5.60 \pm 0.52$ & $4.61 \pm 0.34$ & $5.26 \pm 0.27$ & 5.310 \\
\hline
\end{tabular}

The range of each parameter is 1-7

The present results refer to the possibility of producing milk kefir contains very limited alcohol content with good physicochemical, microbial properties as well as high acceptance rates. Cow's milk inoculated with $2 \% \mathrm{KG}$ and incubated at $24^{\circ} \mathrm{C}$ until $\mathrm{pH}$ fall to $\sim 4.7$ is suitable for controlling kefir alcohol content. Buffalo's milk kefir had the best quality but contained slightly higher alcohol than cow's milk Kefir.

\section{REFERENCES}

Anandharaj, M., B. Sivasankari, and R. P. Rani (2014) Effects of Probiotics, Prebiotics, and Synbiotics on Hypercholesterolemia: A Review. Chinese Journal of Biology, vol. 2014, Article ID 572754, 7 pages. doi:10.1155/2014/572754http://www.hindawi.com/ journals/cjb/2014/572754/abs/
AOAC., (2003): Official Methods of Analysis of AOAC International. 17th Edn., Association of Analytical Communities, Gaithersburg, MD., USA.

Caputi A, Ueda M and Brown T (1968): Spectrophotometric determination of ethanol in wine. Am J Enol Vitic 19: 160-65.

Ertekin, B., and Güzel-Seydim, Z. B. (2010): Effect of fat replacers on kefir quality. Journal of the Science of Food and Agriculture, 90(4), 543-548

Farnworth, E. R. (2005): Kefir a complex probiotic. Food Science and Technology Bulletin: Functional Foods, 2, 1-17.

Geroyiannaki, M., Komaitis, M. E., Stavrakas, D. E., Polysiou, M., Athanasopoulos, P. E., and Spanos, M. (2007): Evaluation of acetaldehyde and methanol in greek traditional alcoholic beverages from varietal fermented grape pomaces (Vitis vinifera L.). Food Control, 18, 988-995. 
Hruškar M and Milana Ritz N. V. I (1995): Aroma profiles and sensory evaluation of yogurt during storage. Paper contributed 1st Slovenian International Congress "Milk and Dairy products", Portorož, 09-20/22.

Kang, K. M. Park, C. S., and Lee, S. H. (2013): Effects of Dtagatose on the growth of intestinal microflora and the fermentation of yogurt. J. Korean Soc. Food Sci. Nutr. 42, 348-354.

Kasenkas, H., Dinkci, N., Seckin, K., Kinik, O. and Gonc, S. (2011): Antioxidant properties of kefir produced from differentcow and soy milk mixtures." J. Agric. Sci. 17, 253-259

Lees G.J. and Jago G.R. (1970): The estimation of diacetyl in the presence of other carbonyl compounds. J. Dairy Res, 37, 129-132.

Leite, A. M. O., D. C., E. M. Del Aguila, T. S. Alvares, R. S. Peixoto, M. A. Miguel, J. T. Silva, and V. M. Paschoalin. (2013b.): Microbiological and chemical characteristics of Brazilian kefir during fermentation and storage processes. J. Dairy Sci. 96:4149-4159.

Leite, A. M. O., Miguel, M. A. L., Peixoto, S. R., Rosado A. S., Silva J. T. and Paschoalin V. M. F., (2013a): Microbiological, technological and therapeutic properties of kefir: a natural probiotic beverage, Brazilian Journal of Microbiology 44, 2, 341-349.

Li Y., Liu T. and He G. (2015): Isolation and Identification of Yeasts from Tibet Kefir. Adv. J. Food Sci. Technol., 7(3): 199-203

Liu, J. R., Y. Y. Lin, M. J. Chen, L. Y. Chen and C. W. Lin. (2005): Antioxidative activities of kefir. Asian-Aust. J. Anim. Sci. 18:567-573.

Magalhaes K T., Dragone G., Melo Pereira G. V., Oliveira J. M, Domingues L., Teixeira J A, Almeida e Silva J.B., and Schwan R. F., (2011b): Comparative study of the biochemical changes and volatile compoundformations during the production of novel whey-based kefir beverages and traditional milk kefir. Food Chemistry 126, 249-253

Magalhaes, K. T., de Melo Pereira, G. V., Campos, C. R., Dragone, G., and Schwan, R. F. (2011a): Brazilian kefir: Structure, microbial communities and chemical composition. Brazilian Journal of Microbiology, 42, 693-702
Otles, S., and Cagindi, O. (2003): Kefir: A probiotic dairycomposition, nutritional and therapeutic aspects. Pakistan Journal of Nutrition, 2, 54-59.

Pearson, D. (1981): The ChemicalAnalysis of Foods, 6th edition. Chemical Publishing Co. Inc., New York.

POP G., Apostu S., Salanţa L., ROTAR A. M., Sindic M., Mabon N. and Socaciu C., (2014): Influence of Different Growth Conditions on the Kefir Grains Production, used in the Kefiran Synthesis. Bulletin UASVM Food Science and Technology 71(2)

Sarkar S (2008): Biotechnological innovations in kefir production: a review. Br. Food J 110:283-295

Sarkar, S. (2007): Potential of kefir as a dietetic beverageA review. British Journal of Nutrition, 109, 280 290.

Taminme A. Y. and Robinson R. K. (1999): Yoghurt; science and technology. Woodhead Publishing Ltd and CRC Press LLC. Cambridge, England, pp. 273-286.

Van der Walt and Yarrow, D., (2009): Methods for the isolation, manteinance, classification and identification of yeasts. In: Kregervan Rij, N.J.W. Ed.., The Yeasts: A Taxonomic Study. $3^{\text {rd }}$ edn. Elsevier, Amsterdam, pp. 45-104.

Wang M and Bi J (2008): Modification of characteristics of kefiran by changing the carbon source of Lactobacillus kefiranofaciens. Journal of the Science of Food and Agriculture J Sci Food Agric 88:763-769

Witthuhn, R. C., Schoeman, T., and Britz, T. J. (2004): Isolation and characterization of the microbial population of different South African kefir grains. International Journal of Dairy Technology, 57, 3337.

Wszolek, M., Tamime, A. Y., Muir, D. D., and Barclay, M. N. I. (2001). Properties of kefir made in Scotland and Poland using bovine, caprine and ovine milk with different starter cultures. LWT Food Science and Technology, 34, 251-261.

Yoo S. H., Seung K. S., and Yoon S. S., (2013): Physicochemical Properties of Kefir Manufactured by Two-Step Fermentation. Korean J. Food Sci. An. Vol. 33, No. 6, pp. 744-751

Yuksekdag, Z. N., Beyatli, Y., and Aslim, B. (2004): Metabolic activities of Lactobacillus spp. strains isolated from kefir. Nahrung, 48, 218-220

\footnotetext{
التحسين من نوع اللبن والعوامل الفيزيائية للحد من محتوى الكفير من الكحول.

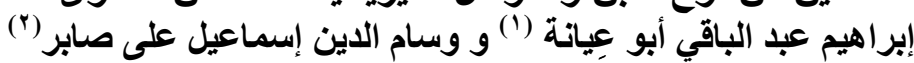

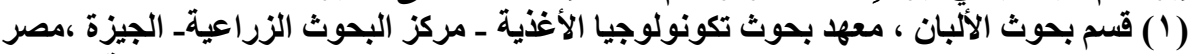

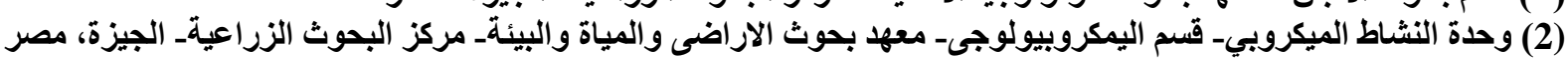

برغم الفو ائد الصحية الكثيرة لمشروب لبن الكفير ، إلا أن وجود نسبة كحول به نتثى كثير من المستهلكين عن تتاوله، لذا هَدفَ هذا

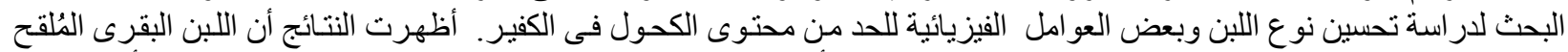

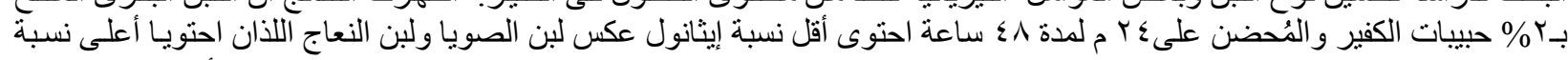

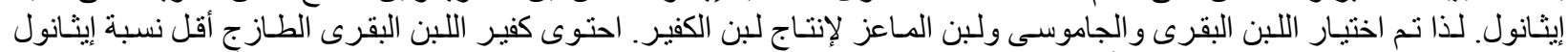

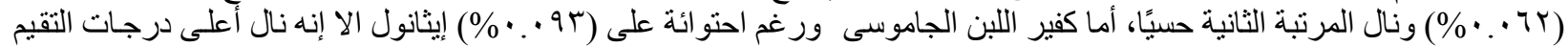

